\title{
A Igreja de N. S. do Rosário dos Pretos
}

\author{
Nara H.N. Machado *
}

Creio que uma das grandes dificuldades que os estudiosos dos acontecimentos e produções do passado enfrentam é a própria ação de homens que, quando não desprezam, simplesmente ignoram o valor de certos fatos ou objetos. Ou manifestam uma vontade deliberada e interessada em apagar determinados rastros e testemunhas. Como diz Walter Benjamin: "Assim como a cultura não é isenta de barbárie, não o é, tampouco, o processo de transmissão da cultura." ${ }^{1}$ Estes problemas, estas dificuldades, são ainda mais agudos no Brasil em tudo que é relacionado com a escravidão e com a vida, cultura e produções da população de origem africana. Daí a importância deste Simpósio que busca resgatar estes aspectos de nosso passado e aprofundar o seu conhecimento.

Felizmente, hoje - também nesta área e aqui no sul do país muitos pesquisadores trazem novos aportes, desvendando mitos que a historiografia oficial se encarregou de cultivar. Assim, a imagem de que a escravidão teria sido, no RS, mais macia, desaparece para ceder lugar à realidade de que aqui - sem dúvida, com especificidades - o negro também foi considerado uma besta de carga, um objeto, uma coisa para dar o máximo de lucratividade a seu senhor.

Tampouco consegue subsistir a versão de que, no Sul, o negro teria sido passivo, submisso. Esta imagem, diante de novas pesquisas e análises - e destaco os trabalhos de Mário Maestri neste sentido - esta imagem cede lugar àquela do negro inconformado, rebelde, que procurou resistir diferenciadamente à sua coisificação, à escravidão. As formas de

* Arquiteta e mestra em História pela PUCRS. 
resistência foram muitas. E, sem dúvida, uma delas residiu na tentativa de manutenção de hábitos e crenças do país de origem. Um exemplo - que constitui o objeto de minha comunicação - é a história e o significado da Igreja de Nossa Senhora do Rosário dos Pretos.

\section{A origem da antiga Igreja N. Sra. do Rosário}

Quem, em Porto Alegre, descer a Vigário José Inácio em direção à Otávio Rocha, se defrontará, à direita, no número 402 , com um prédio pesado, sem originalidade e sem graça. Trata-se da atual Igreja do Rosário que foi construída na década de 50. Poucos sabem - ou melhor, a esmagadora maioria das pessoas não sabe - que anteriormente, ali, no mesmo local, existiu uma outra igreja que, se estivesse de pé, teria 160 anos de idade! Demolida no início da década de 50, esta primeira igreja nasceu de uma iniciativa de negros - muitos escravos - sendo também quase que totalmente construída por eles, no afã de levantar um espaço priviligiado ao culto de sua padroeira, Nossa Senhora do Rosário.

$\mathrm{Na}$ origem da proposta e da construção desta igreja está a dança dos negros - escravos e libertos - na frente e dentro da Igreja Madre de Deus (no local onde se encontra a atual catedral), que ocorria no filtimo quartel do séc. XVIII e início do séc. XIX, pelo menos duas vezes ao ano, no Natal e um dia após, na passagem do aniversário de N. Sra. do Rosário dos Pretos, padroeira da Irmandade do mesmo nome. Ao som de instrumentos nativos (gauzás, tambores, marimbas e urugungos e outros), os negros dançavam repetindo "bailados das terras de origem". ${ }^{2}$ Os negros eram oriundos de um candomblé, o Candomblé da Mãe Rita da Várzea e da Irmandade do Rosário, acima referida, sobre a qual falarei logo a seguir.

Esta tentativa - a dança - de cultivar ritos dos países africanos no permitido espaço do culto cristão pode ser considerada como um momento de resistência à opressão e aos valores de uma nova cultura identificada com o dominador, garantindo ao negro um espaço e identidade próprios.

Contudo, a dança e o barulho incomodavam. Sabe-se, conforme Guilhermino César, que as legislações municipais da época proibiam qualquer sinal de batuque, salvo com licença das autoridades policiais $e$ do senhor do escravo. A este particularmente desagradava "ver as suas bestas de carga se cansando à toa, nas umbigadas de noite adentro; isso 
lhes tirava a energia para o trabalho". ${ }^{3}$ Freqüentemente havia prisão para os escravos e multa (e até prisão em alguns códigos mais exigentes) para o dono do estabelecimento ou do escravo: a dança era permitida apenas nos dias festivos.

Mas, conforme colocado, esta tentativa, na atual Praça da Matriz, de manter ritos originais, incomodava e bastante. Assim, de acordo com Athos Damasceno, "com o correr dos dias [...] a tolerância dos brancos acabou por esgotar-se. E os menos indulgentes irritados com a companhia incômoda e pressionando o vigário da Matriz, trataram de enxotar dali a escravaria importuna". ${ }^{4}$

Ao que tudo indica, a proibição formal do entăo vigário José Inácio dos Santos Pereira ocorreu no final de 1809. Portanto, a busca de um novo local para manter seu ritual está na origem da construção, pela Irmandade do Rosário, de um prédio próprio, que seria a então futura Igreja N. Sra. do Rosário conhecida também como N. Sra. do Rosário dos Pretos ou simplesmente Igreja dos Pretos.

Aqui cabe um parêntese para abordar a Irmandade do Rosário.

\section{Irmandade dos pretos}

Sabe-se que as irmandades foram um dos espaços procurados pelos negros, tantos escravos como libertos. Permitidas e incentivadas pelo senhor branco bem como pela Igreja, constituíram-se principalmente numa tentativa de integração do escravo em seu novo habitat. Inclusive, eram consentidas também por induzirem à expectativas de conquista gradual da liberdade através da alforria, possível de ser comprada com os fundos da irmandade. Entretanto, é inegável que - e quero salientar: principalmente no seu surgimento - configuraram-se também como espaço de resistência, limitado sem dúvida, mas cujos limites não eram de todo controlados pelo senhor. Ao que parece, com o tempo foram gradativamente moldadas e acabaram totalmente controladas, dentro das regras impostos pelos governantes".

A Irmandade do Rosário não fugiu deste quadro. Bastante antiga, seu caminho foi tortuoso. Sua origem remonta ao século XVIII, em Portugal, donde teria sido levada à África pelos catequisadores. Dali teria vindo aportar ao norte do Brasil, de onde se expandiria para o resto do país. No Rio Grande do Sul, foi formada em 1786, quase que exclusivamente por negros, a maioria escravos. Sabe-se que em seu início 
contava com 220 membros: destes, 100 eram livres, 16 forros e 104 escravos" ${ }^{6}$ Este número é surpreendente, considerando-se que o número de habitantes de Porto Alegre naquela ocasião mal beirava os $3000 \mathrm{e}$ confirma o apelo proporcionado entre os escravos por uma irmandade cuja padroeira era justamente uma santa dos negros - "Oxum-dolô".?

Tudo indica que no início não havia maiores exigências para a admissão na irmandade. $\mathrm{O}$ elemento negro era preponderante, apesar de brancos também serem admitidos. Entretanto, o regimento interno que então vigorava não foi aceito pelas autoridades - exigência ou imposição para o funcionamento legal das confrarias, que revela o grau de ingerência do governo nas mesmas. Apenas em 1827 (data da inauguração da igreja) um novo regimento foi aprovado, colocando exigências antes inexistentes, ao menos formalmente. Entre estas verifica-se, por exemplo, a obrigatoriedade de que brancos e pretos livres fossem "catholicos romanos sem a menor suspeita de heresia", com boa conduta moral, abonada por três irmãos da Mesa da Irmandade. E os escravos apenas seriam aceitos com a apresentação de uma licença, por escrito, de seus senhores. O grande número de licenças guardadas no arquivo da Irmandade confirma o apelo que esta exercia entre os escravos. Outra exigência existente, à nível de formação da "Diretoria" da Irmandade, era de que o rei e a rainha fossem de cor preta enquanto o tesoureiro deveria ser de cor branca.

Mesmo sem um estudo mais aprofundado, fica claro o surgimento de regras que não favoreciam os escravos, pois remetiam formalmente sua adesão à Irmandade à boa vontade do senhor. Além disso, estas regras tornavam obrigatória a participação do elemento branco na composição da direção da entidade, e, portanto, sua ingerência na vida e no dia-a-dia da mesma.

Quanto aos fundos da Irmandade, no início eram bastante escassos, oriundos quase que exclusivamente da contribuição dos seus integrantes. Aos poucos se ampliaram, provindo também de esmolas, da cobrança de serviços religiosos e principalmente de doações, algumas vultuosas, incluindo até terrenos e prédios, que a Irmandade alugava.

\section{A construção da Igreja dos Pretos}

Dito isto, voltando à construção da Igreja do Rosário, seu início remonta a 1817. A atual rua Vigário José Inácio era então conhecida 
como rua do Bandeira, antigo morador da mesma. A igreja construída tornou-se um referencial e o nome da rua acabou mudando para rua do Rosário, como permaneceu muito tempo.

$\mathrm{O}$ apelo à construção de um espaço que pretendiam próprio mobilizou muitos escravos e libertos. Consta que era "freqüente no tempo da construção verem-se pelas ruas da cidade pretos e pretas, carregando pedras, tijolos, madeiras, encontradas ou esmoladas aqui e ali para a nova capela [...] inclusive muitos iam trabalhar gratuitamente aos domingos". 9

Até nos candomblés, os fundos eram recolhidos. Além de esmolas, serviços gratuitos e contribuições dos integrantes da Irmandade, os recursos foram oriundos de doações, algumas de grande porte. $\mathrm{O}$ próprio terreno foi parte doado, parte adquirido. Nenhum recurso foi recebido do governo. Isto tem sua importância num momento em que a união entre o Estado e a igreja era ainda bastante grande. Recorde-se que o governo provincial transferia, freqüentemente, consideráveis somas à construção de igrejas.

Em que pese brancos terem participado dos trabalhos de construção, e possível verificar, através da folha de pagamento dos trabalhadores envolvidos, que a imensa maioria correspondia a pardos, pretos forros e escravos, comprovando que foram os negros a quase totalidade dos que edificaram o novo templo.

\section{Um marco histórico}

Quanto à Igreja do Pretos, em si, as descrições, fotos e desenhos que sobreviveram à sua demolição falam da simplicidade e dignidade de uma construção, tendendo ao barroco colonial. Mas, permanece desconhecido o nome do autor (ou dos autores) do projeto.

Encravada entre outros prédios, o local não a beneficiava. Como bem coloca A. Damasceno, a Igreja do Rosário "se levantava em rua estreita e rasa que não lhe favorecia a vista nem a aparência. Uma pena! Porque, bem merecia ela ser contemplada, - com seus doze metros de altura, suas duas torres quadrangulares, seu corpo central dotado de três portas na parte inferior e três amplas janelas na superior, seu campanário servido de seis sinos e, em cima, o frontão em curva e, em baixo, o adro lajeado guarnecido de pilares de alvenaria e gradis de ferro". 
Uma outra descrição detalhada da igreja, feita antes da demolição, destaca as duas torres com sua "beleza singela e impressionante" que, "bem proporcionadas" davam movimento ao conjunto. A originalidade de certos detalhes é sublinhada, como os pequenos respiradouros de bronze, que se destacavam na extrema simplicidade das portas de entrada. Eram tão pequenos que mais pareciam um enfeite! $O$ emblema da irmandade - um rosário encimado por uma coroa - encontrava-se situado na cartela da porta central, que era um pouco mais alta que as demais. ${ }^{10}$ Os velhos coqueiros existentes na frente da igreja certamente conferiam-1he um enquadramento perfeito. Ao todo eram cinco. Mas, infelizmente, foram abatidos em 1910. O motivo alegado foi que atrapa-lhavam o trânsito e o tráfego na frente do prédio.

Tudo indica que o interior da igreja era bastante pobre, despojado de maiores ornamentos. Além do altar principal, onde se encontrava uma escultura da Santa do Rosário, esculpida em madeira, havia mais quatro altares laterais - "sendo dois escantilhados ocupando os ângulos formados pelas paredes da nave e do vão do cruzeiro. Dezessete imagens ali se achavam entronizadas, algumas delas valiosas peças da torêutica portuguesa, como a de N. S. do Rosário", ${ }^{11}$ já referida. A simplicidade dos altares também é destacada nos relatos: "[...] apesar do esmero posto na obra pelo mestre, por sinal desconhecido que os executou [...] nem mesmo poderiam ser tidos como trabalhos de talha, embora não fosse, de simples carpintaria. Eram mais um pouco - eram boas peças de marcenaria levadas à termo com um capricho, habilidade e gosto evidentes."12

As obras da igreja foram concluídas em 1827. Isto é, foi vitoriosa a tentativa dos negros de construir um espaço próprio para a sua padroeira. Mas, deve-se destacar que, quando a igreja foi concluída, aqueles ritos que estiveram na raiz de sua origem já não mais existiam na sua totalidade em Porto Alegre. ${ }^{13}$

A conservação da igreja foi bastante dificultada pela precária situação econômica da Irmandade. Contudo, em 1896, 1909 e 1911, reparos de monta foram feitos. Muitos objetos de valor histórico significativo encontravam-se no pequeno museu, no fundo e nos lados de igreja, tais como imagens, o velho órgão de fole, objetos de prata, castiçais, jarras, bacias, candelabros, etc. bem como os próprios livros da irmandade. 


\section{A destruição a Igreja dos Pretos}

Problemas de má administração, brigas internas e com o clero, disputas com as demais irmandades, levaram gradativamente a Irmandade do Rosário à falência. Assim, ela foi obrigada, em 1930, a firmar um compromisso, através do qual entregava a administração de seus bens e da Igreja à paróquia, que trabalhava sob a orientação da Cúria Metropolitana.

Durante várias décadas, uma intensa polêmica envolveu a questão da pertinência ou não da manutenção da Igreja do Rosário. Contudo, as posições pela sua demolição envolviam diretamente determinadas autoridades do clero, que já antes de 1930, estavam interessadas na construção de um templo maior e mais moderno. Argumentavam que era a igreja mais central de Porto Alegre, portanto a mais freqüentada, logo deveria ser mais ampla. Estas posições escoraram-se principalmente no parecer de uma comissão de engenheiros de Porto Alegre, feito em 1934, segundo o qual a parte aproveitável da igreja era muito pequena. De nada adiantaram as pressões dos inúmeros admiradores da igreja e de sua história. Tampouco adiantou o fato da igreja já constar da relação dos bens tombados pelo Serviço do Patrimônio Histórico e Artístico Nacional (SPHAN). Para nada serviu o parecer do arquiteto paulista Paulo Barreto, enviado pelo Ministério da Educação, que concluiu pela viabilidade da igreja, desde que, obviamente, as obras de restauração necessárias fossem empreendidas. De nada adiantou o argumento de várias testemunhas da época, de que a igreja era sólida e poderia perfeitamente ser restaurada. ${ }^{14}$

Frente às pressões da Mitra Arquidiocesana, o Presidente da República, na ocasião, Getúlio Vargas, assinou um decreto, em 1941, determinando o cancelamento da Igreja N. Sra. do Rosário dos Pretos do SPHAN. Contudo, o velho templo só foi demolido no início da década de 50, quando iniciaram os trabalhos de construção da nova igreja.

Os altares assim como as imagens que pertenciam ao patrimônio da Irmandade do Rosário foram, então, leiloados.

Para finalizar, cabe dizer que, ganha a batalha pelos demolidores, Porto Alegre perdeu e perdeu duplamente: não apenas um dos monumentos históricos mais antigos desapareceu, mas também uma página ali materializada da história dos oprimidos. 


\section{Notas}

* Esta comunicação retoma, desenvolve e aprofunda um trabalho da autora publicado o Diário do Sul, Suplemento especial sobre "100 Anos de Abolição", Porto Alegre, 7-8 de maio de 1988, no 7 .

1. BENJAMIN, Walter. "Sobre o conceito da história", tese n 7. In Magia e técnica, arte e política. Ensaios sobre literatura e história da cultura. Obras escolhidas. São Paulo, Brasiliense, 1987. Vol. 1. p.225.

2. MAZERON, Gaston Hasslocher. Notas para a História de Porto Alegre. Porto Alegre, Globo, 1928. p.15.

3. CESAR, Guilhermino. "O batuque proibido". In: Correio do Povo, "Caderno de Sábado", Porto Alegre, 03 de abril de 1976. O caráter "mágico" de certos ritos africanos, como a dança do batuque, bem como sua origem, talvez "a mais antiga manifestação artística da humanidade" são lembrados, por este autor, neste artigo.

4. DAMASCENO, Athos. Artes plásticas no Rio Grande do Sul. Porto Alegre, Globo, 1971. p.49.

5. Ver CASTANHO, M. Regina; NUNES, M. Regina. "A Irmandade de N.S. do Rosário e S. Benedito". In: FLORES, Moacyr (org.). Cultura afro-brasileira. Porto Alegre, EST-SLB, 1980. p.37. FREITAS, Décio. "Irmandades negras". In: Escravos e senhores de escravos. Porto Alegre/Caxias do Sul, EST-SLB/UCS, 1977. p.91.

6. CASTANHO et alii, op. cit., p.37 e sq. BAREA, Mons. José. Histórico da Igreja N.S. do Rosário de Porto Alegre. 1941. Datilografado, não editado. p.13. Encontra-se no Arquivo da atual Igreja.

7. LAYTANO, Dante. A Igreja e os Orixás. Porto Alegre, Editora da Comissão Gaúcha do Folclore, s/d. Vol. 29. p.38-9.

8. BAREA. Op. cito, p.52.

9. DAMASCENO. Op. cit. p.50.

10. MEDEIROS, José Cruz. "A Igreja do Rosário de Porto Alegre". In: Sul América, Cia. Nacional de Seguros de Vida. Rio de Janeiro, julho/set. de 1949, n 117. p.19.

11. DAMASCENO. Op. cit., p.50.

12. Idem, p.51.

13. MAZERON. Op. cit., p.15. Segundo BAREA. Op. cit., p.59, as fogueiras na frente da igreja, por ocasião de eventos festivos, continuaram até 1871.

14. Segundo MAZERON, G. Hasslocher. "Reminiscências de Porto Alegre". In: Correio do Povo. Porto Alegre, 6 de janeiro de 1946. p.3. 